\title{
INTERNET SERVICES IN THE PROJECT ACTIVITIES OF STUDENTS
}

\author{
Vera I. Toktarova ${ }^{1 *}$ and Dina A. Semenova ${ }^{2}$ \\ ${ }^{1}$ Assoc. Prof., PhD, Mari State University, Russian Federation, toktarova@yandex.ru \\ ${ }^{2}$ Senior Lecturer, Mari State University, Russian Federation, dinasemenova@gmail.com \\ ${ }^{*}$ Corresponding Author
}

\begin{abstract}
The article considers the issues connected with the use of internet technology services in the project activities of students of higher educational institutions. It characterizes the principles of implementing project activities, types of project-based learning, reveals its particular features. The authors distinguish such kinds of projects as foresight, social, technological, innovative, and investment ones. They define the groups of Internet services in accordance with their didactic functions and assignment in the educational process (services of administration and managing the learning processes, services of developing the content of the learning activity, services of provision and support of learning activity, communication and feedback services, information services). The article describes the possibilities of Internet technology services for project implementation at all stages of its lifecycle.
\end{abstract}

Keywords: project, project activities, Internet project, Internet technology service, Federal State Educational Standard of Higher Education (3++), higher education, student, teacher.

\section{INTRODUCTION}

At the present stage of development of the world community, the requirements for the level of specialists' training in any field of professional activity have significantly increased. Thus, according to the Federal State Educational Standard of Higher Education $(3++)$, a graduate who has completed a bachelor's degree program must acquire a universal competency UK-2 from the category "Project Development and Implementation", along with other competencies. In other words, a student should be able to determine the range of tasks within the set goal and choose the best ways to solve them, based on existing legal norms, available resources and restrictions.

In addition, the competency approach, which is one of the main educational approaches of the present time, involves such educational activities that will allow each participant of the educational process to build their own individual trajectory that meets their internal needs and motives.

The competency approach involves the use of interactive teaching methods in the process of developing students' competencies, including project competency. The formation of project competency occurs during 
the implementation of project activities. Its introduction into the practice of modern higher education can provide a high level of professional competence of students.

This confirms the paramount importance of using Internet technologies in the process of forming project competency.

\section{INTERNET SERVICES IN THE ORGANIZATION OF STUDENTS' PROJECT ACTIVITIES}

\subsection{Project Activities of Students}

From our point of view, project activity is a joint activity of students working on an effective solution of a given task throughout the project lifecycle, from the problem statement to the result. Project activities are implemented in accordance with the following principles:

- Step-by-step character: dividing the entire process of solving a problem into stages and gradually achieving the result, a step-by-step transition from the idea to its specialization, and then to the algorithm of achieving and implementing it. Moreover, each subsequent action is based on the results of the previous one;

- Cooperation: combining the efforts of all project participants to solve the problem;

- Predictability: focus on the future state of the object;

- Productivity: necessity to focus on getting a meaningful and real result;

- Regulation: mandatory completion of all stages of the project lifecycle;

- Feedback: necessity to receive information about the efficiency of project activities after each stage of its implementation and, if necessary, to adjust it;

- Self-development: focus on not only the project subject and its activity, but also the formation of new projects as a result of achieving goals;

- Prospects: achieving a positive difference between the desired state of the project subject (what it should be) and the actual state (what it is).

J. Henri, engaged in research of the project system of education, analyzes the attitude of European university students to project activities (Henry, 1994). Students note such positive results of this work as the development of initiative, deeper insight into the research subject, the ability to work independently, the development of intellectual skills, the ability to present the product of creative activity, and the development of new types of activity.

He also notes that after shifting to a project-based learning technology, one of the biggest challenges many teachers face is the need to give up some degree of control over students. Many traditional practices remain the same, but they are reviewed in the context of the project.

\subsection{The Concept of the Project and its Peculiar Features}

Global project technology is based on working together to solve a problem, or, in other words, working on a project.

Modern scientific literature abounds with various definitions of the concept of 'project'. Let us compare interpretations from foreign and Russian literature.

Thus, S.I. Ozhegov dictionary defines the term 'project' as an idea or a plan. E.S. Polat gives a more detailed definition of the project, meaning the activity to achieve a new result within a set time, taking into account certain resources (Polat, 2001). V.N. Funtov defines the project almost identically, saying that it is a purposeful, time-limited activity carried out to meet specific needs in the presence of external and internal restrictions and the use of limited resources (Federal Law, 1999).

The above mentioned definitions and existing project management standards allow defining the following project features:

- Presence of a specific goal (result): goal definition is the first stage of project activity; sometimes the main goal of the project is achieved by means of obtaining the intermediate goals that also should be determined in advance; 
- Project uniqueness: it can relate to the project as a whole, as well as to its individual features (technologies, methods, tools, etc.);

- Limited time: any project has its own beginning and end, the duration can be from several hours to decades; project completion is usually associated with achieving the set project goal or when it is determined that it cannot be achieved;

- Limited resources: first of all, it means that any project has its own budget and the project should be implemented within its framework.

After analyzing more than 15 definitions, it was revealed that the parameter presence of a specific goal is found in $100 \%$ of definitions, limited time - in $81.3 \%$, project uniqueness - in $75.0 \%$, limited resources - in $68.8 \%$.

It is important to note that the project is accomplished on a one-time basis, so a recurring activity can not be considered as a project because, otherwise, it turns into a process. None of the project stages imply a return to a particular point of the project, although the activity can be repeated.

The main goal of the organization of project activities is to create conditions when a student has the opportunity to acquire communication skills by working in groups of students with different interests, as well as the development of research skills (the ability to generalize, observe, analyze, hypothesize). This activity is aimed at ensuring that the student spends most of the time working on the project on independent activities with various resources outside the educational institution.

The Education 2030 roadmap, presented by the Agency for Strategic Initiatives, predicts that the traditional models of the educational system will be broken or eliminated within the period 2022-2030 (Gretchenko, 2010). The main focus is on the foresight projects.

The term 'foresight' means 'prediction', 'looking into the future'. According to the definition of American expert B. Martin, foresight is a systematic attempt to look into the long-term future of science, technology, economy, and society in order to identify areas of strategic research and define generic technologies that promise to bring the largest economic and social benefits (Gretchenko, 2010).

The main goal of developing a foresight project is to find the alternative ways to develop the object of forecasting, that is to determine possible options for the future. Foresight projects are broader in their content than common projects. In addition to goal setting, project creation involves the determination of the ways of its achievement. Foresight projects do not limit the creative potential of students, allowing them to present a certain concept of development, or just a vector that determines the long-term work direction, as a result of their work. The peculiar feature of foresight projects is the involvement of experts from the related fields into the work process. Such collaboration helps to generate more ideas, develops teamwork skills and the ability to jointly find solutions that improve the foresight project participant's own strategies.

In addition to getting a standard result (obtaining and spreading new knowledge), foresight projects are also aimed at creating a unified view of the situation and developing informal relationships between their participants (teamwork skills). Foresight projects are always focused on developing practical actions to achieve the selected strategic goals. All mentioned above allows the efficient introduction of the technology of creating foresight projects into the educational process, contributing to the organization of team work, where the participants offer their own vision of the future revealing their creative potential.

In addition to foresight projects, in recent years to such types of projects as social, technological, innovative and investment ones are under special focus.

Social project is a strategy aimed at solving an urgent social problem. Its implementation will contribute to improving the social situation in a particular team, region, or society (Nikonova, 2015). For students, the implementation of such a project contributes to their establishment in public life through the practical solution of topical social problems. From a variety of social projects, we can distinguish idea-projects (creating new activities, practices, communities, etc.), problem-projects (focus on social problems that were suppressed or ignored for various reasons, etc.), and function-projects (solving real social problems).

Technological project is a single summary or a whole set of documents being the result of the design process (Oleshkov, 2006). The term 'technological design' came to the sphere of educational science from the field of industry, where it refers to the development of optimal technological solutions and necessary organizational conditions for performing technological processes and works. Technological projects can consist of drawings accompanied by a description that includes various calculations. Technological solution 
includes measures aimed at upgrading various solutions, including architectural and engineering design solutions, to meet the conditions of a specific production process.

Innovative project is a set of timed works and events united by a single goal. Its topic is the creation and promotion of new high-tech products to the market. It is mandatory to specify those responsible for the implementation of the project or its parts, the resources used and the sources (Bykovsky, 2011). The concept of an innovative project has a complex structure, so it can be characterized both as the form of targeted managing the innovative activities and its processes, and the set of documentation necessary for introducing innovations. The full lifecycle of any innovative project consists of such enlarged stages as 'science-production-consumption', which implies that the idea of the innovative project should be based on scientific and marketing research, and production should be supported by scientific achievements and adapted to the consumer.

Investment project is a work that includes a justification of the economic feasibility of the project and capital investments in it, the scope and timing of this activity, a description of practical actions for investment (business plan), the necessary design and estimate documentation developed in accordance with the legislation of the Russian Federation and approved standards (norms and rules) (Federal Law, 1999). The investment project includes design and estimate documentation compiled in accordance with the requirements of applicable standards, or a business plan. One of the features of the investment process is the uncertainty of its costs and results, and the degree of this uncertainty is not constant and can vary significantly.

Each project, regardless of its type, consists of a number of stages that make up the project lifecycle.

Project lifecycle is the designation and disclosure of the sequence of all phases (stages) of its implementation from the idea (birth) till the disappearance (death) (Burkov, 1994).

There is no generally accepted concept of project lifecycle phases as each project is unique. Thus, in accordance with GOST R 54869-2011, project management consists of such processes as initiation, planning, organization of execution, control, and completion of the project. It should be noted that there are basic key stages of the project lifecycle that are common to almost all projects, including projects in the field of education:

- Search stage: defining the subject of the project, searching and analyzing the problem, setting the project goal;

- Analytical stage: collecting and analyzing the information, searching for the optimal way to solve the problem, building an algorithm to achieve the result, analyzing the available resources;

- Practical stage: implementing the algorithm for achieving project goals, quality control, making (if necessary) changes to the project implementation process;

- Control stage: analyzing the project implementation results and assessing of the quality of implementation;

- Presentation stage: preparing and presenting the project, defining the opportunities for further use of the project results.

\subsection{Internet Services in the Organization of Project Activities}

The popularity of project activities is also increasing due to the emergence of new educational tools (including Internet technologies) aimed at its effective implementation.

It is necessary to emphasize that the introduction of Internet technologies in project activities has led to the emergence of new types of projects which are Internet projects.

Internet project is

- A project with an important mission to develop a mechanism for organizing network interaction in the context of education (Ivanova, 2012);

- A flexible pedagogical tool that can be represented by a wide variety of ways of organizing and conducting activities and that can be used to solve many teaching tasks (Yarmolinskaya, 2016).

There are the following types of Internet projects: 
- Training telecommunication project is a joint (with a common problem, goal, methods and methods of activity to achieve a common result) training, cognitive, creative or game activity of students using computer telecommunications (Polat, 2001);

- Telecommunication educational project is a joint, organized activity of a certain team (scientists, teachers, students) implemented using telecommunication technologies. This activity is aimed at achieving a consistent pedagogical result and is time-limited (Akhayan, 2000);

- Distance multimedia Internet project is a technology of organizing educational activities according to predefined stages, using network communications for interaction of its participants (Adamsky, 2013);

- Mobile Internet project is a joint activity using mobile Internet technologies aimed at achieving a unique result within a set time, taking into account certain resources;

- Smart Internet project is a flexible Internet project that involves a large number of sources, maximum variety of multimedia, the ability to quickly and easily adjust to the level and needs of a student. It is managed and accessible from anywhere.

So, the Internet project is based on the joint activities of the project team members using the Internet technologies. Attracting Internet technologies to project activities helps to organize joint activities of students to create a product of project activities, ensure the interaction within a team and the constant growth of the quality of project work.

Internet technologies are used at all stages of the project lifecycle: search, analytical, practical, control, and presentation.

Thus, during the search stage of the project, the Internet can become a source of information through its information resources, which provide students with not only an access to a huge amount of text information (social network services for storing multimedia resources), but also an opportunity to organize joint search and analysis of solutions to such problems (chats, e-mail), exchange experience (blogs, tools for storing bookmarks), and identify weaknesses and strengths of the project being implemented, at the same time motivating its further development.

The analytical stage structures the information, identifies the key concepts, models the relationship between them (knowledge maps), organizes search and research works (geoservices) and constant communication of project team members, which can be expressed as a panel discussion in the network community (blogs, WikiWiki), as well as simple communication and feedback (chats, e-mail).

The practical stage of the project lifecycle arranges processes of storing, searching, transmitting, processing, and sharing information in various formats (geoservices, webinars, social networks, social network services for storing multimedia resources), as well as joint network discussion on the project, communication of project team members (chats, e-mail, blogs, webinars, and video conferences).

The control stage involves constant communication within the project group (chats, e-mail, social messengers, blogs), search and elimination of errors (Internet information resources, geoservices), formation of a knowledge map of the implemented project and reflection of relationships inside and outside the project (knowledge maps), joint discussion of the project, making changes, commenting (WikiWiki, forums).

At the presentation stage, thanks to the visibility and interactivity of multimedia objects being a part of Internet technologies, it is possible to present the project results to the end user at an intuitive level, organize their storage (even with a geographical reference), transmitting and sharing (social network services for storing multimedia resources, geoservices, WikiWiki), and conduct a collective defense and discussion of the results (webinars, video conferences).

The Internet and its social services can also become a platform for organizing and implementing the project, which will allow organizing collective, group and individual forms of work for students (Toktarova, 2018, p. 408). In this case, work on the project will be aimed at developing various skills of students (critical and creative thinking, the ability to navigate the information space, structure and update their knowledge, the ability to identify, justify and find an effcient way to solve the problem).

Thus, the main advantages of using the Internet technologies in project implementation are telecommunications (synchronous and asynchronous virtual communication), free access to the distant sources of information, visibility of the presented material, and the development of operational and critical thinking styles of students. All this is achieved due to the capabilities of Internet technologies, which may be divided into the following groups, according to their main didactic functions and the purpose in the 
educational process:

- Educational process administration and management services implement both external management of students' educational activities and self-management of educational activities;

- Educational content development services contribute to the implementation of the didactic potential of Internet technologies in the educational process and include all services that can be used to create educational objects;

- Services for providing and supporting educational activities are aimed at developing the electronic educational environment of the university, automating the process of information exchange, increasing its productivity at all levels of the educational process;

- Communication and feedback services involve active interaction with information resources of the Internet, as well as with other participants of the educational process, the ability to organize prompt feedback;

- Information services are aimed at ensuring the openness of any objects for comprehensive study, contributing to the expansion of knowledge in all available ways of presenting the educational information.

This division is conditional and may vary, as Internet technology services are fundamentally multi-faceted objects and can be used in different contexts, depending on the required didactic functionality.

Thus, the implementation of project activities using Internet services provides interaction, activation and further growth of students' abilities, development and improvement of abilities in the process of joint activities with adults, mastering a variety of ways to implement creative activities, as well as the inclusion of students in the process of solving feasible problems.

\section{REFERENCE LIST}

Adamsky S.S., Mokievskaya N.E., Zaitsev V.A. (2013). Technology of distance multimedia Internet project. Advances in modern natural science, 10, p. 13.

Akhayan A.A. (2000). Functions of telecommunication technologies in conducting telecommunication educational projects. The Emissia. Offline Letters, 6. http://www.emissia.org/offline/2000/797.htm.

Burkov V.N. (1994). Models and methods of managing the organizational systems. Moscow, Nauka, $57 \mathrm{p}$.

Bykovsky V.V., Mishchenko E.S., Bykovskaya E.V. (2011). Management of innovative projects and program. Tambov: Publishing house of Tambov State Technical University, $232 \mathrm{p}$.

Federal Law "On Investment Activity in the Russian Federation in the Form of Capital Investments" (1999) No 39-FZ.

Funtov V.N. (2011). Fundamentals of project management in the company. Saint Petersburg: Piter, 393 p.

Gretchenko A. A. (2010). Foresight as the innovative tool of forecasting and realization of scientific and technological priorities. Vestnik SibSAU. Aerospace technologies and control systems, 1, pp. 154-159.

Henry J. (1994). Teaching through projects. BookEns Ltd, 164 p.

Ivanova V.M. (2012). Internet project as a means of continuous education in the innovative sphere. University complex as a regional center of education, science and culture: materials of the All-Russian scientific and methodological conference. Orenburg, pp. 2500-2506.

Nikonova E.R. (2015). Social designing as a factor of high-quality professional training of architects at the university. Tula, $209 \mathrm{p}$.

Oleshkov M.Y. (2006). The modern educational process: basic concepts and terms. M., Sputnik, p. 134.

Polat E.S. (2001). New pedagogical and information technologies in the educational system. M.: Publishing center "Academiya", $124 \mathrm{p}$. 
Proceedings of SOCIOINT 2020- 7th International Conference on Education and Education of Social Sciences, 15-17 June 2020

Toktarova V.I., Semenova D.A. (2018). Development of information competence of students by means of network and multimedia technologies. Proceedings of ADVED 2018-4th international conference on advances in education and social sciences. Istanbul, pp. 407-412.

Yarmolinskaya M.V. (2016). Internet project as a tool of forming the responsibility of older teenagers. Saint Petersburg, p. 97. 